\title{
Using QR Codes and Mobile Devices to Foster an Inclusive Learning Environment for Mathematics Education
}

\author{
Mike McCabe, Stephen Tedesco \\ Nipissing University, Brantford Ontario, Canada
}

\begin{abstract}
In this paper, students provide insight into their use of Quick Response (QR) codes and mobile devices to assist in mathematics homework efforts. These $Q R$ codes were directly linked to instructional videos related to their unit on fraction algorithms and were hosted on YouTube. In particular, through focus-group interviews, the students identified many strengths associated with the implementation of this research. The strengths include the manner in which the YouTube clips of currently accepted instructional strategies worked to reinforce their classroom learning, how the mobile devices motivated students to complete homework in a variety of non-traditional settings, increased their communication with their classroom teacher, and how these devices engaged parents and siblings in the learning process.
\end{abstract}

\section{Introduction}

This pilot research involved grade 7 students in a mobile learning initiative whereby participants were equipped with immediate access to assistance for mathematics homework through the use of mobile devices. Quick Response codes (QR codes) were used to provide a direct link to multimedia resources that offer visual and audio support to students and parents, as well as provide immediate feedback to the classroom teacher during their grade 7 unit on fractions. This research study investigated the effects of just-in-time mathematics homework support, mediated by mobile devices, on students' motivation, attitude, and efficiency with regards to homework.

\section{Rationale}

The principles and efficacy of homework have been contested for many years [6], [25], [19]. This research can add to the literature and act as a measuring stick to create a more meaningful homework experience for children (and parents). The potential benefits of this research are to create a more inclusive learning environment for all educational stakeholders. Empowered by mobile devices, students may be able to expedite the homework process and at the same time have increased confidence and motivation towards mathematics. This may also provide time for the students to engage in other areas of meaningful interactions such as social and leisure activities, extracurricular, other academic pursuits, and/or family time. At the same time, parents may gain a better understanding of the intricate teachings associated with mathematics in a school environment.

Many difficulties between parent and children at home are due to conflict over homework [12], [20], [24]. This conflict may be due in part to parents' inability to assist when their children experience difficulty with understanding the content. This study is significant in that it attempts to provide access (via QR codes) to video clips of currently accepted pedagogical approaches to learning mathematics through readily available media. Parents now have an opportunity to actively gain an awareness of the learning that takes place within their children's classroom through the use of mobile devices. The knowledge gained through mobile-mediated learning has the potential to translate into more effective assistance with students' homework as well less family conflict regarding homework tasks.

Fractions have been notorious in presenting many difficulties to students. In particular, Asku ascertains that "a common type error in teaching fractions is to have students begin computations before they have an adequate background to profit from such operation.” (p. 375) [1]. As a result, fraction rules can frequently become the focus of rote learning, which produces an artificial feeling of accomplishment and does not encourage the students to think about the meaning of operations. Consequently, the mastery learned in carrying out those operations is quickly lost [1], [11]. Gersten and Chard purport that children should begin to develop their conceptual understanding of number sense at a very young age and, that deficits in this learning can certainly be overcome [11].

Additionally, teachers often feel an obligation to review all assigned homework questions unaware of which posed difficulty to students. This research offers a mechanism to inform teachers about the specific questions (concepts) troubling their students. Armed with this information, there is potential to transform teaching practices and increase homework efficacy.

\section{Research Questions}

Through the establishment of a mobile learning (m-learning) environment designed to support children's mathematics homework endeavours, 
supported by QR codes, this research proposed to investigate the following research questions:

- To what extent does the utilization of $\mathrm{m}$ learning for mathematics homework impact student motivation and efficiency?

- What are the usage patterns of m-learning resources by students for mathematics homework?

\section{Literature Review}

As of 2009, there were 4.7 billion mobile telephone subscribers worldwide - accounting for nearly $70 \%$ of the world's population [14]. The rate at which this growth is occurring is also alarming. From 2006 to 2009 the global mobile subscription rates have increased by nearly $30 \%$ [14]. In the "developed" countries these statistics are even more astounding as the data reveals that mobile cellular phone subscription penetration is over $115 \%$-implying that many people have multiple mobile communication devices (e.g., smartphones, tablets, etc.). As an educator, the implications of incorporating mobile devices into the learning process, dubbed "m-learning", are exciting and it goes without question that the worldwide proliferation of mobile device usage necessitates extensive research in this field.

\subsection{Mobile Learning}

Studies on the use of m-learning devices [24], [23] have shown that students are more engaged in learning, have increased self esteem, selfdirectedness, take initiative and have an increased opportunity to learn at their own pace. Research has shown that mobile learning is effective in increasing participant motivation because it ultimately places the learner in control of what, when, and where they learn [17], [12]. Consequently, mobile devices provide a convenient ubiquitous platform to provide just-in-time learning that is outlined in greater detail below.

\subsection{Computer Mediated Homework Support}

The fact remains that, although research has not been able to prove that homework completion improves student achievement in the junior elementary grades, there is resounding evidence that homework positively affects student achievement in the intermediate and senior grade levels [3]. The crux of the problem is that many students in the intermediate and senior grades do not have access to resources they require to resolve their homework issues. In recent years, organizations and corporations have positioned themselves to fill this need by providing after-hours support centers, payper use tutoring services, and computer aided learning systems (e.g., ASSISTments, MyMathab, etc.). Of these services, computer aided learning systems are most promising since they have proven to support student achievement and do not impose scheduling constraints nor extraneous financial investment given the pervasiveness of personal computers [15], [17].

\subsection{A Mobile Learning Theory to Support Math Homework}

In addressing concerns regarding mathematics homework, the use of mobile learning devices appears to be a natural fit. First and foremost, is that a theory of mobile learning must be established based on "the assumption that learners are continually on the move” [22]. Secondly, m-learning theory must recognize that considerable learning happens in non-traditional learning environments. Finally, as with any learning theory, it must also be grounded in theories of the learning sciences which state that effective learning is: learner centered, knowledge centered, assessment centered, and community centered (National Research Council, 1999). These statutes support a social constructivist learning approach that "views learning as an active process of building knowledge and skills through practice within a supportive community” [22].

\subsection{Quick Response Codes in Teaching and Learning}

Quick response codes (QR codes) are twodimensional bar codes that when scanned by a QR code reader (e.g., a cellular phone camera) can initiate a request to transfer information (e.g., URLs, text messages, emails). QR codes have been chosen in this research study because they provide a universal, convenient, compact, and cost-effective method to transmit information to mobile devices.

Thus far, the applications of QR codes in the field of teaching and learning has been limited, used by some instructors in slide presentations to direct students to website. Many scholars see the potential for using QR codes to direct students to RSS feeds, lecture podcasts, and other just-in-time resources [10].

\subsection{Parental Involvement in Homework}

What appears to be universal in the literature is that parents can have a significant impact on their children's academic achievement-- if they understand their role. Research has indicated that students reap many benefits from parental involvement in education. Comer and Haynes claim that parental involvement is "now widely accepted as 
desirable and even essential to effective schooling" (p. 271) [5]. Becher states that parent participation in the schools is "critical in facilitating children's development and achievement and in preventing or remedying educational and developmental problems [3]. Christenson, Hurley, Sheridan, and Fenstermacher report that, many studies have found home environment and parents' interaction with their child concerning schooling to be the greatest contributors to academic success. They state that "parental participation impacts a student's level of success more than any curriculum reform, selfesteem-building activity, computer technology, or other innovation. It is more significant to school success than family income or education" [4].

Most adults who have been mathematically miseducated themselves (had less than optimal teaching and learning opportunities as children) believe that mathematics is the performance of set procedures invented by others [3]. They have learned-- and expect others to learn-- mathematics as a set of rigid rules invented by others. They simply do not understand mathematics well enough to appreciate when it has been learned well. As a consequence, it is extremely difficult for schools to implement authentic reform because teachers and administrators not only must educate students but also must reeducate parents to understand and support reform.

Weisbaum found that parents remember elementary school mathematics as memorization, drill, and practice and beyond that there was some kind of mysteriousness in higher math. A study by Hradnansky that included parents in the mathematics learning of their children by providing interactive math homework found that students were returning to school with comments such as "My parents didn't know how to do it," "We don't have (materials)," or "My parents said they didn't know why we have to do math like this." Also, one of the problems leading to difficulty in helping their children with homework was that parents questioned the current math curriculum and instruction being used in the classroom...the goals are in sharp contrast to traditional goals and objectives for students in mathematics [13].

\section{Research Informing the Design}

The theoretical perspective for this investigation is grounded in learning theory research related to the influence of school and family on child development and m-learning. Balli, Demo and Wedman state that "homework can be an example of a joint activity in that teachers develop and grade homework assignments, students are expected to complete them, and parents or other family members are expected to monitor, discuss, or help” (p. 150) [2]. Since the learning environment schema proposed in this study involves providing support material that will be accessible through a mobile device, it is important to consider the principles of m-learning. With respect to m-learning, we draw from Sharples, Taylor and Vavoula who model the interplay between a technological tool, control, context, and communication using activity theory [22].

\section{Research Methodology}

The study involved students in grade 7 mathematics classrooms at private schools in Toronto, Ontario, Canada. The study was conducted over a three-week period during which time the students were being taught a unit on "fractions".

\subsection{Participants}

In total, this pilot study had 14 participants: 5 females and 9 males. Discussions with the classroom teachers identified that all students were working toward successful completion of the grade seven mathematics program. Because the focus of this study is the participatory use of mobile devices to support mathematics homework, comparing the changes in the academic standing of the participants is beyond the scope of this investigation. This stated, the researchers did not delve into the students' grades in mathematics.

The concepts introduced by the teacher included, in order, comparing fractions, equivalent fractions, simplifying fractions, converting fractions, and algorithms with fractions. The unit on fractions was chosen due to the historic difficulty it has presented to students (and teachers). The education profession has been struggling to teach not only students but also teachers how better to understand rational numbers and operations performed with them. The scaffolded concepts introduced with this unit provide an ideal opportunity for students to refer to requisite knowledge and strategies presented in the series of videos. Restated, if, during the lessons on "addition of fractions", students required a refresher on equivalent fractions, the associated QR code and video is readily available to them. Each of the 3-5 minute videos used accepted pedagogy including the introduction of concrete materials, (ex. fraction strips, number lines...) to reinforce a conceptual understanding and then, related the instruction to the procedural skills necessary for mastery of the concepts. Again, there were reminders in each video to review videos on previously taught concepts to compliment new instruction. Great efforts were made to link the strategies used by the classroom teacher to those presented in the videos.

The unit of study involved seven instructional periods and five homework assignments. Short videos, ranging from approximately two to seven minutes in length, were published on YouTube by 
the researchers to demonstrate the core concepts being evaluated in each homework assignment, and then accessed by the participants through the use of a QR code reader application on their mobile device (iPhone). Each homework assignment was augmented with a sheet of QR codes linking students to support videos specific for that homework task. In total, 10 videos were created by the researchers, in cooperation with the classroom teacher to support the learning of concepts related to each of the topics.

This study is theoretically rooted in a mixed methods approach to inquiry- the surveys are quantitative and focus group interviews are qualitative [7], [8]. Darbyshire, MacDougall, \& Schiller argue that using multiple methods is a "valuable approach that does not merely duplicate data but also offers complementary insights and understandings that may be difficult to access through reliance on a single method of data collection.” [6].

The qualitative component consisted of focus group interviews with students. These interviews focused on the use of mobile learning technologies as a mechanism to engage participants in mathematics homework, and an opportunity to elaborate on responses obtained in the quantitative component described below. In addition, participants were asked to comment on the use of the QR codes by family members and friends. The students also were given the opportunity to provide feedback in an effort to refine the research for future studies.

The quantitative component of the research consisted of participant surveys and solicited information to answer the following research questions:

1. What are students' perceptions of the use of mobile devices?

2. Did the use of the mobile devices and support videos change homework practices to provide a learning environment that was inclusive of educational stakeholders such as parents, teachers, and students?

3. Was there an effect on the students' level of confidence and motivation in completing mathematics homework?

Also included here is the data collected via cell phone use logs indicating usage patterns for each participant.

\section{Data Collection}

The teacher assigned participants nightly homework questions from their traditional mathematics textbook and workbook. If they encountered difficulty with their homework, students used their mobile device to gain access to digital support materials (using the provided QR codes- see Figure 1). This support material consisted of videos (hosted on YouTube) of a trained educator teaching the concepts addressed in class and related to the homework assignment. The participants had the freedom to interact with the support materials as little or as much as they deem necessary, creating a personalized learning experience. It should be noted that although we only mention support videos in this design, there is no restriction on what resources can be provided to a student who requests help (e.g., it could be a link to an interactive exercise, an application that can run on their mobile device, or a collection of such resources).

Homework: Workbook Pg. 92, Questions 2 and 4

Use fractions strips or a number line to add the following:

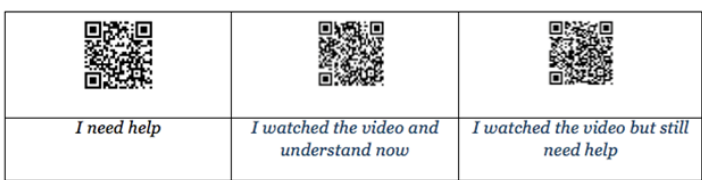

Figure 1. Example of assigned homework question with QR code

Once viewing was complete the participant would reattempt the homework problem with which they had difficulty. The participant then provided feedback to the teacher by scanning the appropriate QR code (either "I watched the video and understand now", or "I watched the video but still need help.") that sent an email to their teacher. This feedback provided the teacher with instant knowledge regarding each participant's request for help and data that they could use to gauge the progress of individual students, or the group as a whole. The teacher could also use this data for reflective practice and informed data driven decision-making regarding future teaching practices (e.g., reduced or increased time on homework review, alternative instructional strategies, etc.).

\section{Results}

Table 1 illustrates the viewership of the videos by topic/concept and provides a general sense of the range of assistance required by the students.

Table 1. Topics of study and unique viewing frequency

\begin{tabular}{|l|c|}
\hline Video/Topic & Number of Unique Viewers \\
\hline 1. Comparing Fractions & 13 \\
\hline 2. Equivalent Fractions & 11 \\
\hline 3. Simplifying Fractions & 7 \\
\hline 4. Adding Fractions & 9 \\
\hline 5. Subtracting Fractions & 4 \\
\hline 6. Converting Mixed Numbers to Improper Fractions & 5 \\
\hline 7. Converting Improper Fractions to Mixed Numbers & 5 \\
\hline 8. Adding Mixed Numbers & 6 \\
\hline 9. Subtracting Mixed Numbers & 6 \\
\hline 10. Multiplying Fractions & 2 \\
\hline & Total \\
\hline
\end{tabular}


This table indicates that all participants accessed the video titled "Comparing Fractions", and all but two accessed the video on "Equivalent Fractions", etc. Most notable is the frequency of unique viewers for the core competency videos (comparing, equivalent, and simplifying fractions). In reviewing the dates in which these videos were accessed, it is worthy to note that some students accessed the core competency videos later in the unit when they were dealing with more difficult problems involving multiple concepts (e.g., students referred to equivalent fractions when introduced to the concept of adding fractions).

Table 2 depicts the viewership of the support videos by individual students. This identifies that the videos received 68 unique views, an average of 6.8 views per video. Unique views refers to each time a video was accessed by one of the mobile devices. This implies that on any given night, over half of the participants required assistance through the support videos to complete their mathematics homework in this unit. The range of unique views for the participants was from 1 to 10 with a mode of 7 while the median was 6 . This leads to potential for the classroom teacher to identify students who are experiencing difficulties across most/all concepts (e.g., there was one student who accessed all the support videos, one who accessed 8 videos, etc.).

Table 2. Frequency and Total Views by Student

\begin{tabular}{|l|c|c|c|c|c|c|c|c|c|c|c|}
\hline Number of Unique Views & $\mathbf{1}$ & $\mathbf{2}$ & $\mathbf{3}$ & $\mathbf{4}$ & $\mathbf{5}$ & $\mathbf{6}$ & $\mathbf{7}$ & $\mathbf{8}$ & $\mathbf{9}$ & $\mathbf{1 0}$ \\
\hline Frequency & 2 & 1 & 0 & 2 & 1 & 2 & 3 & 1 & 0 & 1 & \\
\hline Total Views & 2 & 2 & 0 & 8 & 5 & 12 & 21 & 8 & 0 & 10 & 68 \\
\hline
\end{tabular}

After completing the study the participants were asked to complete an anonymous 25-question survey providing candid insight into their impressions and experiences. Table 3 provides and account of the frequency of responses for key results.

Table 3. Key Survey Questions Results

\begin{tabular}{|l|c|}
\hline Survey Question & $\begin{array}{l}\text { Frequency } \\
\text { of Response } \\
\text { "Agree" }\end{array}$ \\
\hline $\begin{array}{l}\text { I feel that when I used my smartphone and QR codes for my } \\
\text { homework I was more prepared for the next math class }\end{array}$ & $83 \%$ \\
\hline $\begin{array}{l}\text { I feel that using a smartphone and QR codes allowed me to complete } \\
\text { my homework more effectively }\end{array}$ & $83 \%$ \\
\hline $\begin{array}{l}\text { I feel that my math grades have improved because of the use of } \\
\text { smartphones and QR codes }\end{array}$ & $67 \%$ \\
\hline $\begin{array}{l}\text { I feel that using a smartphone and QR codes allowed me to complete } \\
\text { my homework more efficiently }\end{array}$ & $67 \%$ \\
\hline $\begin{array}{l}\text { I was motivated to do my math homework because I knew immediate } \\
\text { help was available through the QR codes }\end{array}$ & $58 \%$ \\
\hline $\begin{array}{l}\text { I feel that using the smartphone and QR codes was easier than asking } \\
\text { others }\end{array}$ & $67 \%$ \\
\hline $\begin{array}{l}\text { I was less likely to become frustrated with my math homework } \\
\text { because I knew immediate help was available through the QR codes }\end{array}$ & $83 \%$ \\
\hline $\begin{array}{l}\text { I found that my family (parents, guardians, siblings) was more } \\
\text { interested in my math homework as a result of this research }\end{array}$ & $92 \%$ \\
\hline $\begin{array}{l}\text { I found that my family (parents, guardians, siblings) and I have } \\
\text { worked together more on math homework as a result of this research }\end{array}$ & $92 \%$ \\
\hline
\end{tabular}

In the focus group interviews, the participants elaborated on the key areas identified in Tables 1 and 2. In particular, as provided in the few examples below, the students identified how the uniqueness of the resources motivated them, and others, to access the videos. It also provided a quick access reminder of concepts and procedures for completing their homework:

It was great because it (the video) was exactly like in class. Sometimes when I get home I remember only half of what we learned in class so now it's easy to remember the rest. Before, I didn't have any way to help me remember except my notes and sometimes they don't help either.

I always finished my homework because I could use the QR codes. The other codes (linked to e-mail to inform teacher) helped too because our teacher knew we needed help. The smartphones also had a calculator so I used it lots.

I thought it was really cool. I told my sister about it and she even used the QR codes. I got to use them for all my homework. My mom even looked at them and thought my teacher was really good. She said she hoped that I got the same teacher next year.

My mom talked to other parents and my teacher about how to teach math. She really liked that she could watch the videos on her phone too.

I really liked that I didn't have to ask anyone for help and I could rewind the video if I didn't get it the first time. We also could fast forward through stuff we understood. I wish we could do this with our teacher sometimes. The best part was that I was not shy to get help.

\section{Discussion}

It is quite clear from the quantitative and qualitative results that the integration of mobile devices into homework support was valuable to the students. With respect to our first research question regarding student perceptions, there is strong support for a positive view toward the use of the devices. Although accessing student grades was beyond the scope of this research, two-thirds of the students felt that their mathematics scores would increase due to their participation. This indicates an increased confidence in their perception of math knowledge, something that plays a significant role in achievement. 
Our second research question was concerned with how the use of the mobile devices and support videos changed homework practices to provide a learning environment that was inclusive of educational stakeholders such as parents, teachers, and students? There was ample support for students being motivated to complete homework with 58\% reporting that they were more motivated to complete their homework. This may, of course, be attributed to the mobile devices being new. It is beyond the scope of this research to measure the lasting effects of the mobile devices. In addition, it was obvious that usage by family members increased engagement in school mathematics. Historically, the benefits of parental involvement in children's education is well documented [9], [12], [13], [4], [5]. The survey results indicate that $67 \%$ of the participants found it easier to use the mobile devices and QR codes than asking others, while $83 \%$ of the participants found it easier than referring to their class notes. Students also made mention of the versatility of the devices and how they were completing homework in nontraditional settings (car and recreational facilities). The phone logs also indicated that students were accessing the support videos early in the mornings (before 7:00 a.m.) and late at night (after 10:00 p.m.) - times when traditional support (parents or teachers) may not be available to them. There was universal agreement during the focus group interviews that the QR codes and YouTube videos had great potential to assist in all areas of students' academic life.

The results discussed above relate directly to the third research question dealing with students' level of confidence and motivation in completing mathematics homework. Eighty-three percent of the participants stated that they were more prepared for the next class after having used the support videos. Over two thirds of the group found that they completed their homework more effectively due to the use of the technology. Most importantly, perhaps, $83 \%$ of the participants said that they were less likely to become frustrated with their math homework because they knew immediate help was available through the QR code without the added embarrassment of having to ask for assistance in front of their peers and teacher. One could then make the assumption that there is a positive correlation between the feelings associated with efficient and effective homework completion, feeling less frustrated with feelings of confidence and motivation, particularly in children in this age group.

\section{Limitations}

As with any pilot research, a number of limitations existed. These included:

- While the participants were drawn from two separate grade 7 classes we recognize that the small sample size reduces the generalizability of our results.

- Students indicated that because their access to the videos was being monitored they felt apprehensive to scan the QR codes that provided feedback to the teacher.

This reduced the classroom teachers' awareness of student needs (e.g., with this information the teachers could have altered the amount of instructional time devoted to recapitulation and new learning).

\section{Conclusions}

Homework has a long-standing history in the field of education. This study investigated one approach to mitigate some of the barriers identified in the literature regarding successful mathematics homework completion. The use of mobile devices (smartphones) to provide just-in-time access to mathematics support proved to be beneficial to the participants in this study. Students now have the potential to seek help on-the-go, in environments previously unavailable to them while participating in their academic endeavours. This study opens up discussion regarding the availability and efficacy of the use of mobile technology to assist in these efforts. The study, combined with many other efforts, has the potential to effectively transform teaching and the traditional classroom environment.

\section{Considerations for Future Research}

Given that this was a pilot study, it has already spawned a number of additional areas for future research. In particular, it is essential to explore the impact of the mobile devices, QR codes and YouTube videos on the family dynamic as it relates to homework. As well, a more longitudinal study that investigates the impact of the resources on student learning has great potential here. Additionally, this leads to the potential to explore the use of mobile learning in other academic disciplines. Of course, there is a desire to repeat this pilot study with a larger participant group.

\section{References}

[1] Aksu, M. (1997). Student performance in dealing with fractions. The Journal of Educational Research, 90, 375-380.

[2] Balli, S., Demo, D., \& Wedman, J. (1998). Family Involvement with Children's Homework: An Intervention in the Middle Grades. Family Relations, 47(2), 149-157.

[3] Becher, R. (1986). Parents and schools (Report No. 400-830021). Washington, DC: Office of Educational Research and Improvement. (ERIC Document Reproduction Service No. ED269137) 
[4] Christenson, S. L., Hurley, C. M., Sheridan, S. M., \& Fenstermacher, K. (1997). Parents'and school psychologists' perspective on parental involvement activities. School Pyschology Review, 26(1), 111-130

[5] Comer, J.P., \& Haynes, N. M. (1991). Parent involvement in schools: An ecological approach. The Elementary School Journal, 91, 271-277.

[6] Cooper, H. (1989). Homework. New York: Longman.

[7] Creswell, J. (2009). Research design qualitative, quantitative, and mixed method approaches, (3rd Ed.). Thousand Oaks, California: Sage.

[8] Creswell, J. \& Clark, V. (2007). Designing and conducting mixed methods research. Thousand Oaks, California: Sage.

[9] Darbyshire, P., MacDougall, C. and Schiller, W. (2005) Multiple methods in qualitative research with children: more insight or just more? Qualitative Research. 5(4): 417-436.

[10] EDUCAUSE (2009). 7 things you should know about QR codes. Retrieved from http://www.educause.edu/ir/library/pdf/ELI7046.pdf. Date of retrieval: May 4, 2012.

[11] Gersten, R. \& Chard, D. (1999). Number sense: rethinking arithmetic instruction for students with mathematical diasabilities, Journal of Special Education, 51, 133-154.

[12] Ginsburg, L., \& Rashid, H. (2006). Children’s other teachers - their parents. Socio cultural Issues, (2), 499-501.

[13] Hradnansky, T. A. (1999). A family math program to increase parent participation in math homework in primary multiage classroom. Unpublished doctoral dissertation, Nova Southeastern University, Davie, FL.

[14] International Telecommunications Union (2009). The world in 2009: ICT facts and figures. Retrieved from http://www.itu.int/ITUD/ict/material/Telecom09_flyer.pdf. Date of retrieval: April 28, 2012

[15] Kodippili, A., \& Senaratne, D. (2008). Is computer-generated interactive mathematics homework more effective than traditional instructor-graded homework?. British Journal of Educational Technology, 39(5), 928-932. doi:10.1111/j.14678535.2007.00794.x.

[16] Liu, T.-Y., Tan, T.-H., \& Chu, Y.-L. (2009). Outdoor natural science learning with an RFID-supported immersive ubiquitous learning environment. Journal of Educational Technology \& Society, 12(4), 161-175.

[17] Mendicino, M., Razzaq, L., \& Heffernan, N. (2009). A Comparison of Traditional Homework to Computer-Supported Homework. Journal of Research on Technology in Education, 41(3), 331-359.

[18] National Research Council. (1999). How people learn: Brain, mind, experience, and school. Washington, DC: National Academy Press.

[19] Otto, H.J. (1950). Elementary education. An Encyclopedia of Educational Research (2nd Edition). New York: Free Press.

[20] Pezdek, K., Berry, T., \& Renno, P. (2002). Children's Mathematics Achievement: The Role of Parents' Perceptions and Their Involvement in Homework. Journal of Educational Psychology, 94(4), 771-777.
[21] Pfeiffer, V., Gemballa, S., Jarodzka, H., Scheiter, K., \& Gerjets, P. (2009). Situated learning in the mobile age: Mobile devices on a field trip to the sea. ALT-J: Research in Learning Technology, 17(3), 187-199. doi:10.1080/09687760903247666

[22] Sharples, M., Taylor, J., and Vavoula, G. (2005). Towards a theory of mobile learning. Proceedings of MLearn 2005 conference.

[23] Schwabe,G., \& Göth, C. (2005). Mobile learning with a mobile game: Design and motivational effects. Journal of Computer Assisted Learning, 21(3), 204 216. doi:10.1111/j.1365-2729.2005.00128.x.

[24] Vahey, P. \& Crawford, V. (2002). Palm Education Pioneers Program Final Evaluation Report. Menlo Park, CA: SRI International.

[25] Wildman, P.R. (1968). Homework pressures. Peabody Journal of Education, 45, 202- 204. 